\title{
Control of Surface Chemistry and Electrochemical Performance of Carbon-coated Silicon Anode Using Silane-based Self-Assembly for Rechargeable Lithium Batteries
}

\author{
Hyun Choi, Cao Cuong Nguyen, and Seung-Wan Song*
}

\author{
Department of Fine Chemical Engineering \& Applied Chemistry, Chungnam National University, Daejeon 305-764, Korea \\ *E-mail:swsong@cnu.ac.kr
}

Received May 24, 2010, Accepted July 15, 2010

\begin{abstract}
Silane-based self-assembly was employed for the surface modification of carbon-coated Si electrodes and their surface chemistry and electrochemical performance in battery electrolyte depending on the molecular structure of silanes was studied. IR spectroscopic analyses revealed that siloxane formed from silane-based self-assembly possessed $\mathrm{Si}$-O-Si network on the electrode surface and high surface coverage siloxane induced the formation of a stable solid-electrolyte interphase (SEI) layer that was mainly composed of organic compounds with alkyl and carboxylate metal salt functionalities, and PF-containing inorganic species. Scanning electron microscopy imaging showed that particle cracking were effectively reduced on the carbon-coated $\mathrm{Si}$ when having high coverage siloxane and thickened SEI layer, delivering $>1480 \mathrm{mAh} / \mathrm{g}$ over 200 cycles with enhanced capacity retention $74 \%$ of the maximum discharge capacity, in contrast to a rapid capacity fade with low coverage siloxane.
\end{abstract}

Key Words: Silane-based self-assembly, Carbon-coated Si, Surface chemistry, Electrochemical performance, SEI layer

\section{Introduction}

Silicon (Si)-based materials (e.g., intermetallics, carbon composites) based on alloy reaction with lithium recently have received a particular attention as a next-generation anode materials to replace graphite that is currently used in commercialized lithium-ion batteries, because of larger theoretical specific capacity $3759 \mathrm{mAh} / \mathrm{g}\left(\mathrm{Li}_{15} \mathrm{Si}_{4}\right)$ of $\mathrm{Si}$ at room temperature than that of graphite. ${ }^{1-3}$ A significant crystal structural volume change $(>300 \%)$ during $\mathrm{Li}$ insertion and extraction to/from crystalline $\mathrm{Si}$, which is followed by electrochemical and mechanical disintegration of particles, ${ }^{4-7}$ has however been noticed as a major drawback responsible for poor electrochemical performance. Although the volume change could be reduced with amorphous $\mathrm{Si}$, which lowers activation energy barrier and reduces structural strain when reacting with lithium, a capacity decline during electrochemical reaction was inevitable. ${ }^{6}$ Many approaches of improvement in the electrochemical performance of Si-based materials have been employed, mostly in a manner which suppresses structural volume changes by modifying bulk materials. ${ }^{6}$ Carbon coating on the surface of Si-based materials ${ }^{8,9}$ or Si particles embedded into carbon matrix ${ }^{10-12}$ seems to be one of the most effective methods. Carbon can enhance electronic conductivity of the electrode and accommodate the volume change. With respect to nanostructure control, much efforts have been ongoing for the development of synthetic strategies by tuning the micro- and nano-structures of Si-based materials releasing the structural stress and enhancing the kinetics. ${ }^{13-15}$ Nonetheless, the issues of volume and particle morphology changes seem to be unavoidable, showing the continuous capacity loss with long term $\mathrm{Li}$ insertion and extraction.

Recollecting that lithium ion transport should begin to occur at the electrode/electrolyte interface, structural volume change followed by particle cracking event will accompany the change in active surface area that should be correlated to the surface chemistry of Si-based materials. Consensus regarding the surface chemistry and its relationship with performance are yet to be reached. We found that the Si reacted with lithium saltderived species more actively than carbonate-based organic solvents in the conventional electrolyte, ${ }^{16}$ which was somewhat different interfacial process from that of lithiated graphite that formed a stable solid-electrolyte interphase (SEI) layer composed of primarily organic compounds mostly during initial cycling. ${ }^{17}$ It was claimed that the surface of Si needed to be protected from lithium salt of electrolyte. ${ }^{16}$

Organoalkoxysilane is of our particular interest as a surface modifying agent to $\mathrm{Si}$, since the organoalkoxysilane can form the $\mathrm{Si}-\mathrm{O}-\mathrm{Si}$ molecular linkages with the surface silanol groups of $\mathrm{Si}^{16,18,19}$ The Si-O-Si molecular cross-linking for the formation of siloxane occurs via axial self-assembly following intermolecular condensation; - $\mathrm{Si}-\mathrm{OH}+\mathrm{Si}(\mathrm{R})_{4-\mathrm{x}}(\mathrm{OR})_{\mathrm{x}} \rightarrow-\mathrm{Si}-$ $\mathrm{O}-\mathrm{Si}(\mathrm{R})_{4-\mathrm{x}}(\mathrm{OR})_{\mathrm{x}-1}+\mathrm{ROH}(\mathrm{R}=$ alkyl group $) .{ }^{20}$ The presence of trace water assists the hydrolysis of silanes and equatorial polycondensation on neighboring silane molecules, forming three dimensional (3D) self-assembled siloxane network.

Systematic studies of thin-film model electrode that possesses enlarged surface to volume ratio can provide a clearer insight into self-assembly phenomena, electrode/electrolyte interfacial reaction and electrochemical processes of material, and permit convenient analyses of the SEI composition without complications from carbon and binder additives that are necessary in bulk materials. ${ }^{16,21-24}$ Polymeric binder often gives interfering signals in IR spectroscopic data, which obstructs distinguishing newly formed surface species from the binder. Thin-films prepared with pulsed laser deposition (PLD), which generally possess a strong physical interfacial adherence to electronically conductive substrate, allow the observation of material's intrinsic surface structure and reaction, and inhibit a peel-off 
event of the film during extended cycling in lithium cells. For the surface characterization, we focus on ex-situ IR measurement with attenuated total reflection (ATR) geometry that is very sensitive to surface species and provides direct information on the functional groups of surface molecules. ${ }^{22-26}$

Here we report a surface modification approach to stabilize surface structure and cycling performance of carbon-coated Si thin-film electrode. Surface modification by self-assembly of organoalkoxysilanes with different number of organoalkoxy group and SEI layer formation resulting from electrode/electrolyte interfacial reactions were determined using ex-situ IR spectroscopy with attenuated total reflection (ATR) geometry. Interfacial reaction behavior-performance relationship is discussed.

\section{Experimental}

Films of Si were first prepared on stainless steel substrates with PLD at $200{ }^{\circ} \mathrm{C}$ with 20 min deposition in 5 mtorr of Ar. Deposition utilized a $\mathrm{KrF}$ eximer laser with an energy density of $3-4 \mathrm{~mJ} / \mathrm{cm}^{2}$ at $10 \mathrm{~Hz}$ impinging on a target (ICM Engineering). Film thickness and morphology were evaluated by a field emission scanning electron microscope (FE SEM, Jeol JSM-7000F) at $5 \mathrm{kV}$. The observed film thickness of the asprepared Si film was $47-74 \mathrm{~nm}$. The $10 \mathrm{~nm}$ thick carbon film was coated over the film of $\mathrm{Si}$ (denoted as $\mathrm{C}-\mathrm{Si}$ hereafter) by precision etching coating system (PECS, Gatan Inc. 682 PECS $^{\mathrm{TM}}$ ) with ion beam current of $200-250 \mu \mathrm{A}$. Elemental distribution of $\mathrm{Si}$ and $\mathrm{C}$ over the film was obtained using electron mapping of SEM. The film structure was identified by X-ray diffraction using an X-ray diffractometer (Rigaku D/MAX-2200) with $\mathrm{Ni}$ filtered $\mathrm{Cu} \mathrm{K} \alpha$ radiation at $40 \mathrm{kV}$ and $40 \mathrm{~mA}$, and a scan rate of $1.5^{\circ} / \mathrm{min}$ from 20 to $70^{\circ} 2 \theta$ with $0.02^{\circ}$ steps. Further structural characterization of Si and coated carbon was carried out using Raman spectroscopy. Raman spectral measurement was conducted for 120 - 240 s using a closed prototype Raman cell, where the film surface was placed below the glass window in the glove box, then, the cell was tightly sealed. Raman spectra were recorded using a Raman microscope (Tokyo instrument Co., Nanofinder 30) at ambient conditions, using the $632 \mathrm{~nm}$ line of a He-Ne laser at $1 \mathrm{~mW}$. Backscattering optics geometry with double-notch filter and a standard charge-coupled device (CCD) detector were used to collect, process, and analyze the Raman signal. The size of the laser beam at the sample was less than $200 \mathrm{~nm}$.

In order to examine self-assembly of silanes on the C-Si, several identical as-prepared C-Si film electrodes were immersed in the jars filled with approximately $5 \mathrm{~mL}$ of 1-(trimethylsilyloxy)-1,3-butadiene $\left(\mathrm{CH}_{2}=\mathrm{CHCH}=\mathrm{CHOSi}\left(\mathrm{CH}_{3}\right)_{3}\right.$, Aldrich), methyltrimethoxysilane $\left(\mathrm{CH}_{3} \mathrm{Si}\left(\mathrm{OCH}_{3}\right)_{3}\right.$, Aldrich), and tris(2methoxyethoxy)vinylsilane $\left(\mathrm{CH}_{2}=\mathrm{CHSi}\left(\left(\mathrm{OCH}_{2} \mathrm{CH}_{2}\right)_{2} \mathrm{OCH}_{3}\right)_{3}\right.$, Aldrich) for $3 \mathrm{hrs}$, respectively. Then, the films were separated from the silane solution and thoroughly washed with dimethyl carbonate (DMC, Techno Semichem) for $30 \mathrm{~s}$ and dried in the glove box at room temperature. For the film immersed in tris (2-methoxyethoxy)(vinyl)silane, longer washing of 3 hours with DMC was conducted for further removal of silane moiety. Surface identification for the C-Si obtained after self-assembly reaction with different silanes was carried out with ATR FTIR spectroscopy, using IR spectrometer (Bruker optics IFS66V/S) equipped with a mercury-cadmium-telluride (MCT) detector. Prior to the measurements the films were directly mounted on the closed single reflection ATR unit with a Ge optic in the Ar-filled glove box, then, the FTIR spectra were acquired. There was no moment of atmospheric contamination. Spectral resolution was of $4 \mathrm{~cm}^{-1}$ and a total of 512 scans were co-added.

Electrochemical cells, containing C-Si film electrode as a working electrode with Li reference and counter electrodes, have been used for electrochemical evaluation. The lithium cells with the film electrode were cycled at a constant current of $35 \mu \mathrm{A} / \mathrm{cm}^{2}$ between 0.1 and $1.5 \mathrm{~V} v$ s. $\mathrm{Li} / \mathrm{Li}^{+}$at room temperature, in the electrolyte of $1 \mathrm{M} \mathrm{LiPF}_{6} /$ ethylene carbonate (EC): diethyl carbonate (DEC) with 1:1 volume ratio (Techno Semichem) without or with $5 \mathrm{wt} \%$ silanes as additives, using a multichannel cycler (Wonatech). The cycled films were separated from the lithium cells and thoroughly washed with DMC and dried in the glove box at room temperature for ex-situ characterization. All self-assembly reactions and electrochemical experiments with lithium cells were conducted in the Ar-filled glove box with the water and oxygen contents of about $1 \mathrm{ppm}$. Surface chemistry of the film electrodes obtained after cycling was studied using ex-situ ATR FTIR spectroscopy. Changes in the film morphology of C-Si film electrodes before and after cycling were characterized by ex-situ FESEM and Raman spectroscopy.

\section{Results and Discussion}

Characterization of carbon-coated Si electrode. Surface morphology of the as-prepared C-Si appears smooth in Fig. 1a. Raman spectrum of the film in Fig. 1b exhibits a sharp band at $516 \mathrm{~cm}^{-1}$, characteristic of crystalline $\mathrm{Si}^{27}$ and equally intense and broad bands at 141,320 and $472 \mathrm{~cm}^{-1}$ that are due to amorphous $\mathrm{Si}^{28,29}$ Although the as-prepared Si only film was crystalline, discernable from the XRD pattern (not shown), after carbon-coating the film became partly disordered or amorphous. Also shown is a broad band at around $1500 \mathrm{~cm}^{-1}$ corresponding to graphite-like $\mathrm{sp}^{2}$ carbon (G-band), ${ }^{30,31}$ which indicates that graphite-like carbon is dominant in the coated carbon layer. Fig. 1c and d exhibit elemental distribution of Si and $\mathrm{C}$ atoms in the film. Homogeneous but scattered distribution of $\mathrm{C}$ atoms is indicative of a porous feature of the carbon layer, as often occurs on carbon-coated Si and Si-carbon composite bulk materials. Note that bare $\mathrm{Si}$ of the film could be exposed to electrolyte.

Surface modification of carbon-coated Si electrode. Formation of siloxane between the as-prepared C-Si film and silane was monitored by ATR FTIR spectroscopy. Figure 2 shows IR spectra for the surface of the C-Si film obtained after immersing in three different silanes (Fig. 2a-c) followed by DMC washing. The surface layer of the as-prepared Si before carbon coating showed the IR signature of silanol (-Si-OH) group at 850 - 830 $\mathrm{cm}^{-116,18}$ (not shown). For the film surface immersed in 1-(trimethylsilyloxy)-1,3-butadiene, Fig. 2a' exhibits prominent peaks at 1103 and $1024 \mathrm{~cm}^{-1}$ due to asymmetric stretching modes of Si-O-Si functionality. ${ }^{31-33}$ Sharp peaks at 1268 and $814 \mathrm{~cm}^{-1}$ 

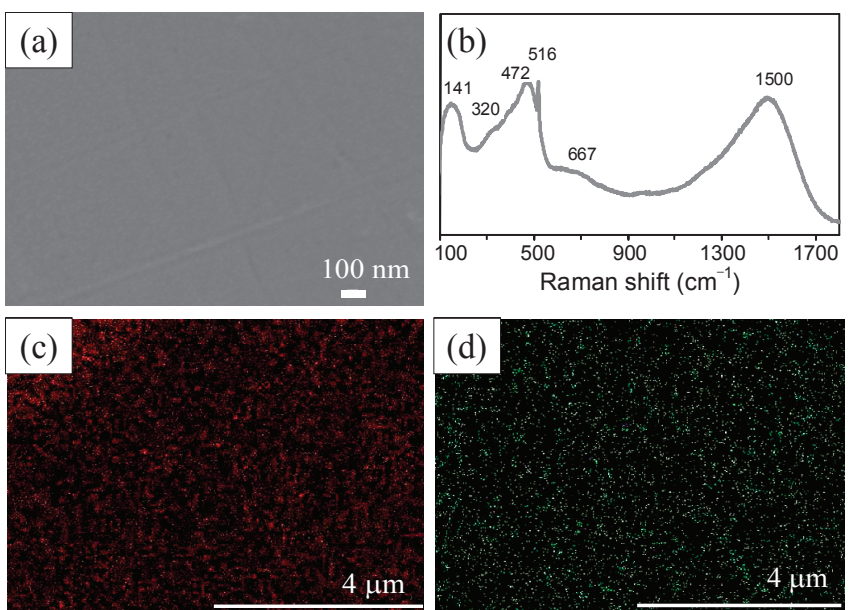

Figure 1. SEM image of surface morphology (a) and Raman spectrum (b) for the as-prepared carbon-coated Si film, and electron mapping results of (c) Si (red) and (d) C (green) elements.

are attributed to deformation of $-\mathrm{CH}_{3}$ from $\mathrm{Si}-\mathrm{CH}_{3}$ group and stretching mode of $\mathrm{Si}-\mathrm{C}$ together with $-\mathrm{CH}_{3}$ rocking, respectively. ${ }^{31,32}$ Signature of silanol group was no longer clearly distinguished and must be used up for self-assembly. This evidences that siloxane formed at the surface of C-Si by self-assembly condensation between surface silanol group and one alkoxy group from this silane, resulting in the formation axial 1D Si-O-Si molecular linkages. Three methyl groups of 1-(trimethylsilyloxy)-1,3-butadiene remains perhaps available for further reaction with electrolyte components or physical interaction with electrolyte or SEI component. Tiny peaks at 2965 - 2851 $\mathrm{cm}^{-1}$ due to $-\mathrm{CH}_{3}$ group support this assignment.

Similar spectral feature was observed for the film immersed in methyltrimethoxysilane in Fig. 2b', except that the peaks at 1108 and $1045 \mathrm{~cm}^{-1}$ due to Si-O-Si group of siloxane became relatively stronger than that of Si-C functionality observed near $830 \mathrm{~cm}^{-1}$. Since three methoxy groups in methyltrimethoxysilane could be consumed for the formation of Si-O-Si linkages, one axial Si-O-Si bond from each silane to the silanol of $\mathrm{Si}$ surface can be produced, whereas two other remaining alkoxy groups are utilized for equatorial condensation between silanes leading to 3D Si-O-Si network. In this case the siloxane chain of Si-O-Si functionality should be longer and branched compared to the siloxane with only axial linkage from single alkoxycontaining silane, thereby, enhances the peaks absorbance and makes the peaks broader. Surface coverage with 3D siloxane network however may be limited because of physical dimension by the presence of porous carbon layer.

With tris(2-methoxyethoxy)vinylsilane the film surface in Fig. 2c', obtained after DMC washing for 30s, shows the peaks for both asymmetric Si-O-C stretching of silane and Si-O-Si functionality of siloxane at 1150,1112 and $1024 \mathrm{~cm}^{-1}$, respectively, ${ }^{31-33}$ referred to the original spectrum of tris(2-methoxyethoxy)vinylsilane. ${ }^{33}$ This indicates that some alkoxy group of silane is utilized for the formation of siloxane, whereas others remained as attached to the siloxane. Other peaks at $2985-2821$ $\mathrm{cm}^{-1}$ for $-\mathrm{CH}_{2}$ - and $\mathrm{CH}_{3}$ stretching and their deformation at $1454-1403 \mathrm{~cm}^{-1}$, and also -O-C group at $1201 \mathrm{~cm}^{-1}$, symmetric Si-O-C stretching at 973 and $846 \mathrm{~cm}^{-1}$ and $783 \mathrm{~cm}^{-1}$ for $-\mathrm{CH}_{2-}$
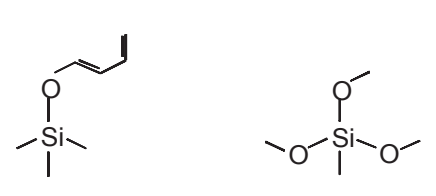

b

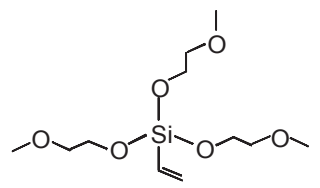

a

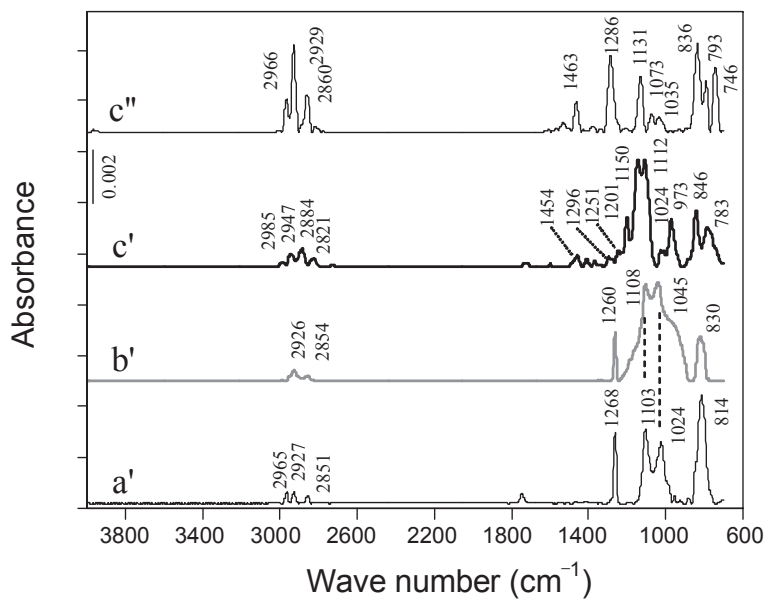

Figure 2. Molecular structure of 1-(trimethylsilyloxy)-1,3-butadiene (a), methyltrimethoxysilane (b) and tris(2-methoxyethoxy)vinylsilane (c). IR spectra for the as-prepared Si film and the carbon-coated Si obtained after immersing in the (a') 1-(trimethylsilyloxy)-1,3-butadiene, (b') methyltrimethoxysilane and (c') tris(2-methoxyethoxy) vinylsilane followed by DMC washing for 30s, (c') washing for $3 \mathrm{hrs}$ and drying.

rocking of oxaethylene chains $-\left(\mathrm{OCH}_{2} \mathrm{CH}_{2}\right)_{2}-\mathrm{OCH}_{3},{ }^{31,32}$ respectively, and $-\mathrm{CH}_{2}$ wagging of vinyl group at $973 \mathrm{~cm}^{-1}$ support the presence of silane moiety. In general, the condensation reactions become sluggish with greater bulk alkoxy group because of steric hindrance. In Fig. 2c', further DMC washing for 3 hrs resulted in a disappearance of the peaks corresponding to the silane moiety. However several sharp peaks, attributed to oxaethylene $-\left(\mathrm{OCH}_{2} \mathrm{CH}_{2}\right)-\mathrm{OCH}_{3}$ of silane, are still discernable. Eventually the film surface became decorated with the organic silane moiety, like "artificial" surface layer. This enlarges surface coverage of siloxane at most among the silanes used in this work. The resultant data ensures that in the presence silane, self-assembly of siloxane occurs on the surface of the C-Si.

Cycling behavior of surface modified electrode. Cycling behavior of the $\mathrm{C}$-Si in the presence of silanes was evaluated using constant current cycling at $35 \mu \mathrm{A} / \mathrm{cm}^{2}\left(\sim 1 \mathrm{C}\right.$ for $\left.\mathrm{Li}_{15} \mathrm{Si}_{4}\right)$ in the voltage region of $0.1-1.5 \mathrm{~V} v s . \mathrm{Li} / \mathrm{Li}^{+}$, where structural stress by amorphization-crystallization of Si was avoided. ${ }^{3}$ The capacities of a lithium cell with C-Si were obtained by calculation based on the film thickness of Si film and coated carbon layer, electrode area $\left(0.283 \mathrm{~cm}^{2}\right)$ and crystallographic densities of Si $\left(2.33 \mathrm{~g} / \mathrm{cm}^{3}\right)$ and carbon $\left(1.4 \mathrm{~g} / \mathrm{cm}^{3}\right)$. Some errors $(c a .10$ $20 \%$ ) in capacity values can come from film thickness evaluation and the use of theoretical crystallographic densities of $\mathrm{Si}$ and carbon. The capacity vs. voltage plots are shown in Fig. 3a-d. Differential capacity plots (Fig. 3a'-d'), obtained from the voltage profiles in Fig. 3a-d, show a better peak resolution of the Si reaction with lithium. In $1 \mathrm{M} \mathrm{LiPF}_{6} / \mathrm{EC}$ :DEC electrolyte in the absence of silane, the first charge (cathodic) curve (Fig. 
(a)

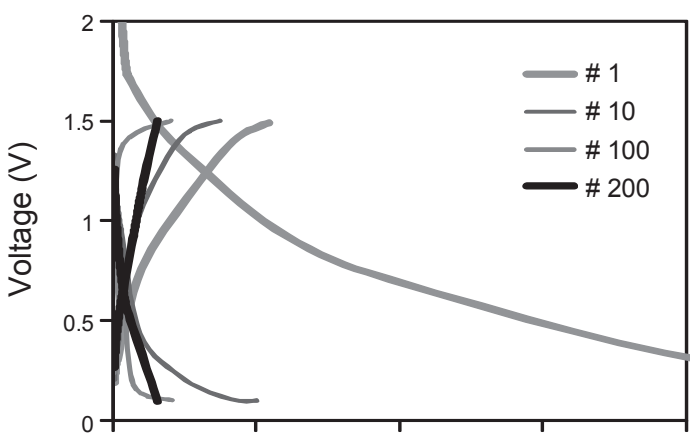

(b)

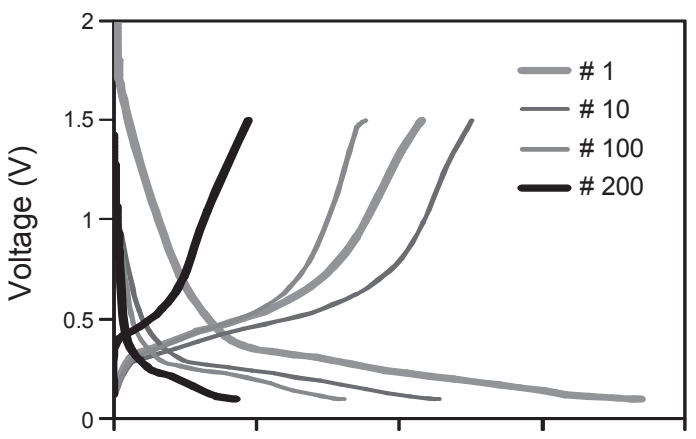

(c)

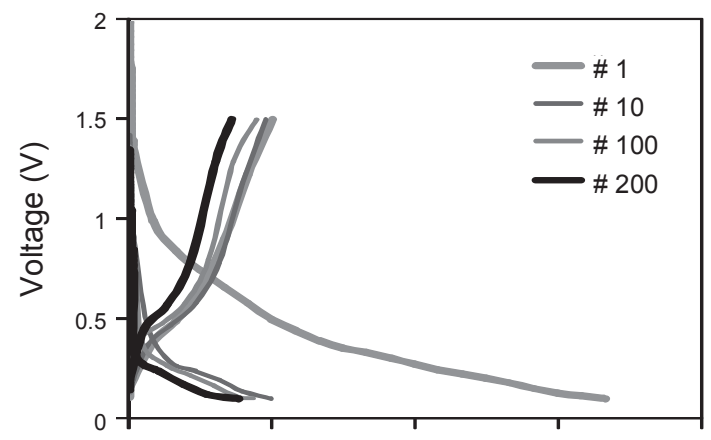

(d)

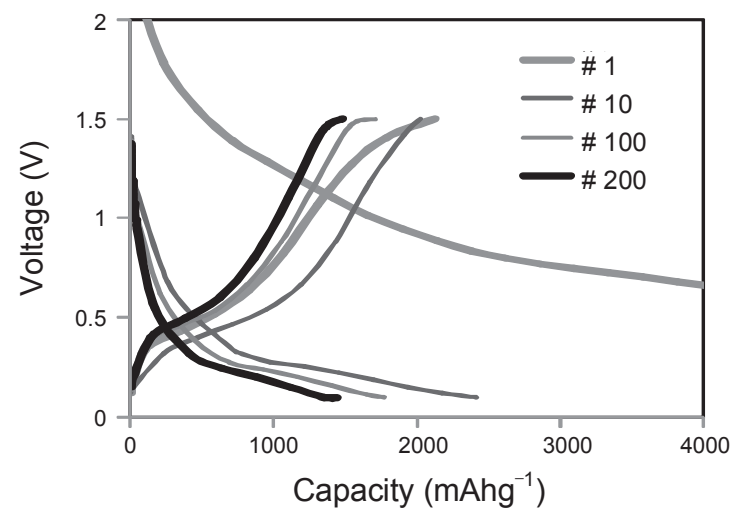

(a')

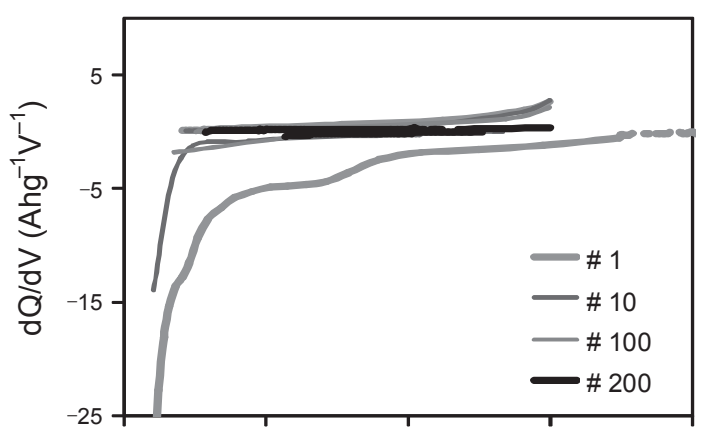

(b')

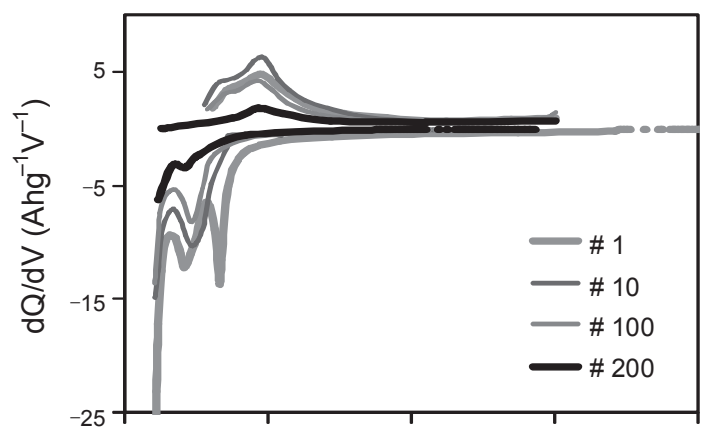

(c')

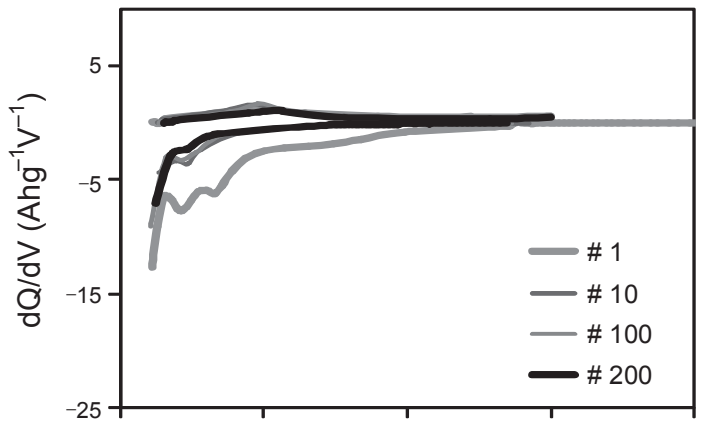

(d')

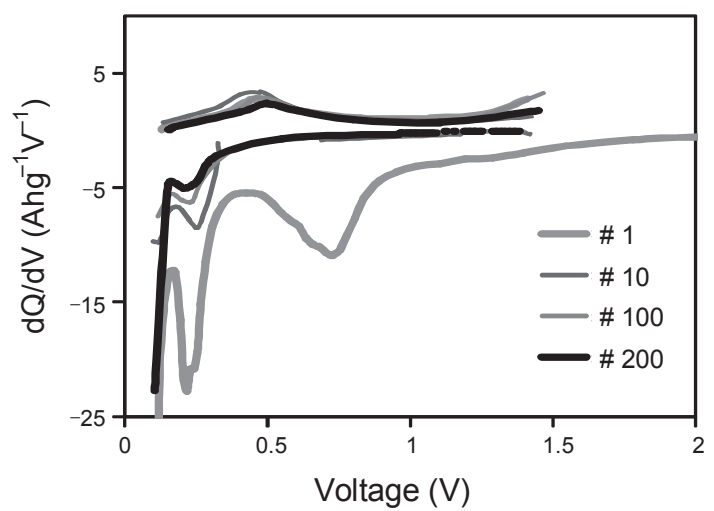

Figure 3. Capacity $v s$. voltage plots of the lithium cells with carbon-coated Si electrode in $1 \mathrm{M} \mathrm{LiPF}_{6} / \mathrm{EC}: \mathrm{DEC}$ without silane (a), and with (b) 1-(trimethylsilyloxy)-1,3-butadiene, (c) methyltrimethoxysilane and (d) tris(2-methoxyethoxy)vinylsilane between 0.1 and $1.5 \mathrm{~V} v s$. Li/Li ${ }^{+}$, and their differential capacity $(\mathrm{dQ} / \mathrm{dV})$ plots (a')-(d').

3a') showed a broad and significant cathodic contribution from 2.0 to $0.5 \mathrm{~V}$, which has been attributed to the reduction of the electrolyte components of EC (calculated reduction potential $1.46 \mathrm{~V} v s . \mathrm{Li} / \mathrm{Li}^{+}$), and DEC (calculated reduction potential $1.33 \mathrm{~V}),{ }^{34,35}$ and decomposed and hydrolyzed species of $\mathrm{LiPF}_{6}$ salt. ${ }^{35}$ Reduction of electrolyte components on the C-Si seems to be severe. The salt of $\mathrm{LiPF}_{6}$ is known to be in the equilibrium as $\mathrm{LiPF}_{6} \leftrightarrows \mathrm{PF}_{5}+\mathrm{LiF}$. The presence of a trace of water in the electrolyte produces $\mathrm{PF}_{3} \mathrm{O} ; \mathrm{PF}_{5}+\mathrm{H}_{2} \mathrm{O} \rightarrow \mathrm{PF}_{3} \mathrm{O}+2 \mathrm{HF}^{36}$ Since both gaseous $\mathrm{PF}_{5}$ and $\mathrm{PF}_{3} \mathrm{O}$ are strong Lewis acids, they can readily react with the $\mathrm{C}$-Si that possesses a plenty of electrons to donate in our operating voltage region, forming $\mathrm{M}-\mathrm{PF}_{5}$ or 
(a)

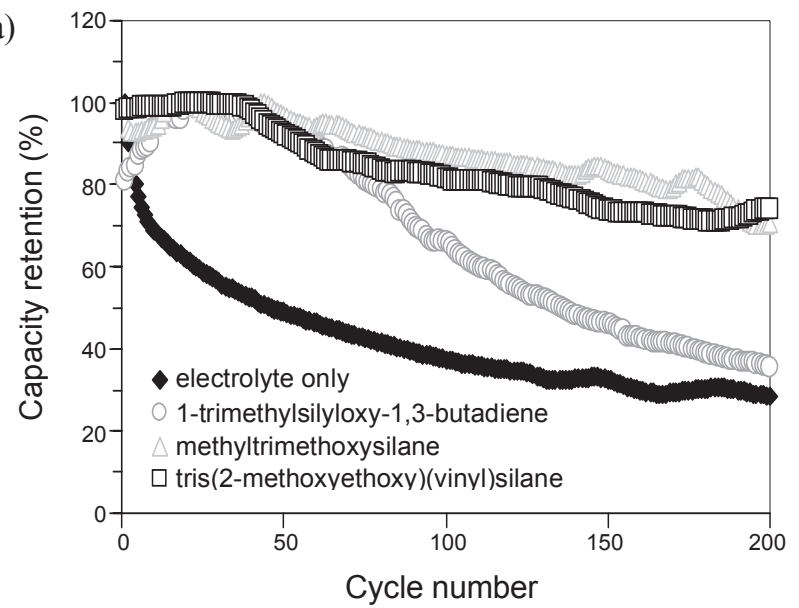

(b)

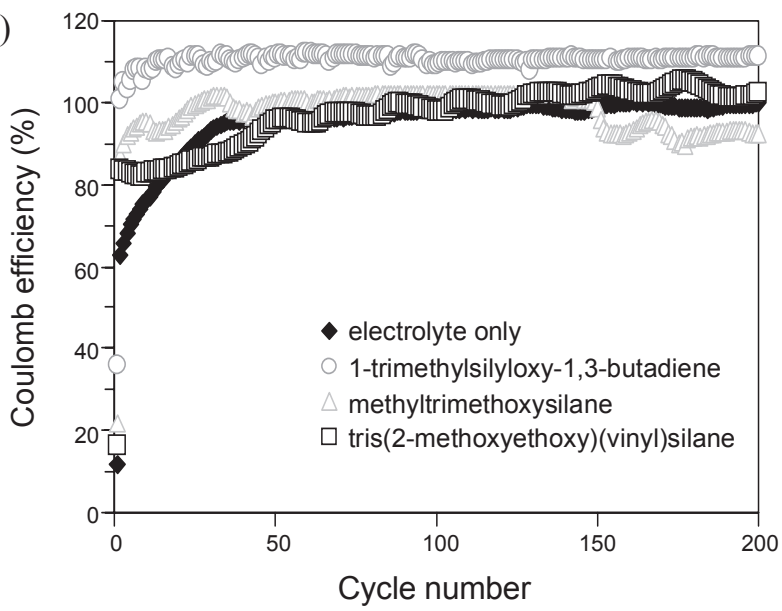

Figure 4. Capacity retention (a) and Coulomb efficiency (b) of the lithium cells with carbon-coated Si electrode without and with silanes, as a function of cycle number.

$\mathrm{M}-\mathrm{PF}_{3} \mathrm{O}(\mathrm{M}=\mathrm{Li} / \mathrm{Si})$ type precipitates followed by participating in the further electrochemical reduction. The HF, the hydrolysis product of $\mathrm{PF}_{5}$, is predicted to etch and modify the surface morphology of the C-Si. At the voltage region below $1.0 \mathrm{~V}$, further reduction of surface species that were formed at higher voltages took place showing still large cathodic contribution, which indicates the reformation of surface composition. This process is followed by the large capacity shoulder at approximately $0.25 \mathrm{~V}$, corresponding to main $\mathrm{Li}$ insertion into amorphous $\mathrm{Si}$, forming $\mathrm{Li}_{3.25} \mathrm{Si}$ and/or the amorphization of $\mathrm{Si}$, consistent with earlier literatures. ${ }^{1,3,37}$ After the first charge process, all the peaks disappeared. Such irreversible capacity loss continuously occurred over 200 cycles, resulting in very low capacity retention $28 \%$ in Fig. 3a-a' and Fig. 4a, and poor efficiencies ((discharge capacity/charge capacity) $\times 100)$ as displayed in Fig. 4b. In addition to electrolyte reduction, irreversibility in Li insertion and extraction should be responsible for this continued irreversible capacity loss.

With 1-(trimethylsilyloxy)-1,3-butadiene, Fig. 3b-b', the $\mathrm{C}-\mathrm{Si}$ shows sharper peaks for $\mathrm{Li}$ insertion and extraction, in contrast to the film without silane (Fig. 3a-a'). The film maintained structural resolution till the $100^{\text {th }}$ cycle despite a large capacity loss to $66 \%$ of maximum capacity. In the first charge curve, Fig. 3b', cathodic contribution down to $0.4 \mathrm{~V}$ is little, in contrary to the film without silane (Fig. 3a'). This reveals that reductive electrolyte decomposition is dramatically reduced. The cathodic peaks between 0.1 and $0.3 \mathrm{~V}$ are due to $\mathrm{Li}$ insertion for the phase change to $\mathrm{Li}_{12} \mathrm{Si}_{7}$ to $\mathrm{Li}_{3.25} \mathrm{Si}^{37}$ On the subsequent discharge process, the anodic peaks at $0.3-0.5 \mathrm{~V}$ are due to $\mathrm{Li}$ extraction toward the regeneration of Si. Self-assembled siloxane from 1-(trimethylsilyloxy)-1,3-butadiene was effective in suppressing electrolyte decomposition and increasing the reversibility in the early cycles. Nonetheless, after $\sim 100$ cycles the film exhibited a disappearance of all the peaks with the occurrence of a drastic capacity decline to $36 \%$ of maximum discharge capacity over 200 cycles (Fig. 4a), with poor efficiencies $>100 \%$ in Fig. 4b. Although silanols at the surface of bare Si and 1-(trimethylsilyloxy)-1,3-butadiene formed self-assembled siloxane, the axial Si-O-Si linkages only and low surface cover- age must be insufficient to endure the changes in structural volume and particle morphology during repeated $\mathrm{Li}$ insertion and extraction. Since the low surface coverage of siloxane allows direct electrode-electrolyte interfacial contact, during discharge the electron transfer from electrode to electrolyte followed by reductive electrolyte decomposition can provide additional discharge capacity to that by delithiation process. This is related to the efficiencies higher than $100 \%$. Silane with a single alkoxy group appears to offer only limited effect on the performance.

In Fig. 3c-c', the C-Si with methyltrimethoxysilane that comprises three methoxy groups exhibited somewhat improved cycling ability compared to single alkoxy-containing silane. The film electrode shows $71 \%$ capacity retention of the maximum discharge capacity at the 200 th cycle but capacities lower than $1000 \mathrm{mAh} / \mathrm{g}$, in Fig. 4a. The 3D siloxane network confers improved surface protection of the $\mathrm{C}$-Si and capacity retention. However, efficiencies in Fig. $4 \mathrm{~b}$ were reduced to $92 \%$ after 150 th cycle. Even though cycling performance was much improved when having 3D siloxane, in contrast to $1 \mathrm{D}$ or absence of siloxane, the ability of surface protection by siloxane in this case appeared to be limited.

For the tris(2-methoxyethoxy)vinylsilane the C-Si showed a remarkably improved capacity retention with enhanced capacity values. In Fig. 3d-d', except the first cycle, the prominent structural resolution is remained throughout the $200^{\text {th }}$ cycle. In the first charge process, Fig. 3d', significant cathodic capacity between 2.0 and $0.5 \mathrm{~V}$ is observed, which is not observed in the following cycles. This is related to the SEI formation by reductive electrolyte decomposition. The - $\left(\mathrm{CH}=\mathrm{CH}_{2}\right)$ vinyl functionality of tris(2-methoxyethoxy)vinylsilane is known to undergo cathodic electro-polymerization around $0.8 \mathrm{~V}$ at the surface of electrode. ${ }^{38,39}$ The polymerization process could increase additionally the cathodic capacity, despite its low concentration level $5 \mathrm{wt} \%$. Large capacities of $1480-2130 \mathrm{mAh} / \mathrm{g}$ and preserved capacity retention of $74 \%$ over 200 cycles in Fig. 4 a should be due to the effective surface protection of the $\mathrm{C}$-Si with high surface coverage siloxane and silane moiety first and then additional passivation with the SEI components. 
Figure 4 compares the impact of the type of silane on the cycling performance of the C-Si. Overall, in the presence of silanes discharge capacities and capacity retention were improved, in contrast to a rapid capacity decline after the first cycle in the absence of silane. However, even in the presence of selfassembled siloxane, the initial irreversibility due to the reductive decomposition of electrolyte components forming the SEI layer (Fig. 3b'-d') was observed in common. Considering that greater cycling performance was obtained when using the silane that contains three alkoxy functionalities with relatively longer organic chain (Fig. 2c-c'), the surface coverage of self-assembled siloxane network was determined to be the key factor affecting cycling performance of the C-Si.

Characterization of the SEI layer using IR spectroscopy. Surface chemistry of the C-Si in the silane-containing electrolyte was investigated by characterizing the surface species produced on the film electrode surface due to cycling, using ex-situ ATR FTIR spectroscopy. Figure 5 shows IR spectra for the C-Si surface obtained after cycling without and with silanes. Tentative assignments to the vibrational modes are made as the following. Note that when the electrodes were rinsed in DMC prior to IR analysis, soluble surface species could be washed off.

After cycling in the electrolyte without silane, Fig. 5a-a', the C-Si surface shows strong IR features below $900 \mathrm{~cm}^{-1}$, mostly originated from inorganic compounds. Predominant peaks below $890 \mathrm{~cm}^{-1}$ are assigned to stretching modes of P-F probably in different molecular bonding nature. The $\mathrm{LiPF}_{6}$-derived compounds, $\mathrm{PF}_{5}$ and $\mathrm{PF}_{3} \mathrm{O}{ }^{16,36}$ must be involved in the formation of PF-containing species and as a consequence LiF salt may form automatically as described above. However LiF is not detectable in the mid-IR region used in this work. The data indicate that PF-containing species (e.g., $\mathrm{M}-\mathrm{P}_{\mathrm{n}} \mathrm{F}_{\mathrm{m}}(\mathrm{M}=\mathrm{Li} / \mathrm{Si})$ ) are the major surface species. This may indirectly indicate that $\mathrm{LiF}$ also forms on the electrode surface. The film also shows the trace of $\mathrm{C}=\mathrm{O}$ for alkyl carbonate metal salt $\mathrm{R}-\mathrm{OCO}_{2}{ }^{-} \mathrm{M}^{\mathrm{n}+}(\mathrm{R}=$ alkyl, $\mathrm{M}=\mathrm{Li} / \mathrm{Si}$ ) and/or $\mathrm{R}-\mathrm{CO}_{2}{ }^{-} \mathrm{M}^{\mathrm{n}+}$ carboxylate metal salt in the region of $1720-1550 \mathrm{~cm}^{-1}$ and $\mathrm{CH}_{3}-\mathrm{CH}_{2}$ - alkyl group at 2960 -
$2800 \mathrm{~cm}^{-1}$, related to the reduction of organic carbonate solvents. $^{16,17,22-24,31,32,40-42}$

With 1-(trimethylsilyloxy)-1,3-butadiene, Fig. 5b-b', the CSi surface also shows strong IR features below $900 \mathrm{~cm}^{-1}$, where they are mostly due to PF-containing inorganic compounds. No signature of Si-O-Si functionality from siloxane between 1000 and $1130 \mathrm{~cm}^{-1}$ is observed. Reminding that the film with 1(trimethylsilyloxy)-1,3-butadiene had only axial 1D Si-O-Si linkages and exhibited a rapid capacity decline around the $100^{\text {th }}$ cycle (Fig. 3b-b' and 4), self-assembled siloxane may be collapsed at some point in the middle of cycling. Then, at the $200^{\text {th }}$ cycle the film surface is eventually covered by only PF-containing species, like the surface composition obtained after cycling without silane.

On the C-Si surface after cycling with methyltrimethoxysilane, Fig. 5c-c', IR signatures from P-F containing species are mainly observed. Trace of some organic species is visible but in a very low absorbance. Tiny peaks due to alkyl and $\mathrm{C}=\mathrm{O}$ group of $\mathrm{R}-\mathrm{CO}_{2}{ }^{-} \mathrm{M}^{\mathrm{n+}}$ carboxylate salts are shown near 1544 $\mathrm{cm}^{-1}$. 16,17,22-24,31,32 Newly appeared tiny peaks at 1307,1153 , $1016,833 \mathrm{~cm}^{-1}$ are ascribed to stretching modes of $\mathrm{P}=\mathrm{O}, \mathrm{P}-\mathrm{O}-\mathrm{C}$ and $\mathrm{P}-\mathrm{F}$ group from $-\mathrm{O}=\mathrm{PF}-\mathrm{OR}$ organic phosphorus-fluorine compounds. ${ }^{31,32,43}$ They are partly overlapped with the peaks at 1108 and $\sim 1045 \mathrm{~cm}^{-1}$ characteristic of siloxane chain, ${ }^{16,31,32}$ in Fig. 2b'. Note that for the C-Si comprising no siloxane or low surface coverage siloxane, inferior cycling performance (Fig. 3a-b) and mainly PF-containing surface species (Fig. 5a-b) were observed. In this context, the presence of mainly PF-containing surface species indicates the limitation in surface protection of siloxane. This is why capacity retention relatively improved but low capacities and a decrease in efficiency in the late stage of cycling (Fig. 4).

On the other hand, cycling the C-Si with tris(2-methoxyethoxy)vinylsilane resulted in a very different spectral feature from those cycled with other silanes. In Fig. 5d-d', signatures from $\mathrm{CH}_{3} \mathrm{CH}_{2}$ - alkyl group at $2960-2850 \mathrm{~cm}^{-1}$ are significantly strong, indicating that organic compounds including alkyl functionality are one of the major SEI components. Lower absor-
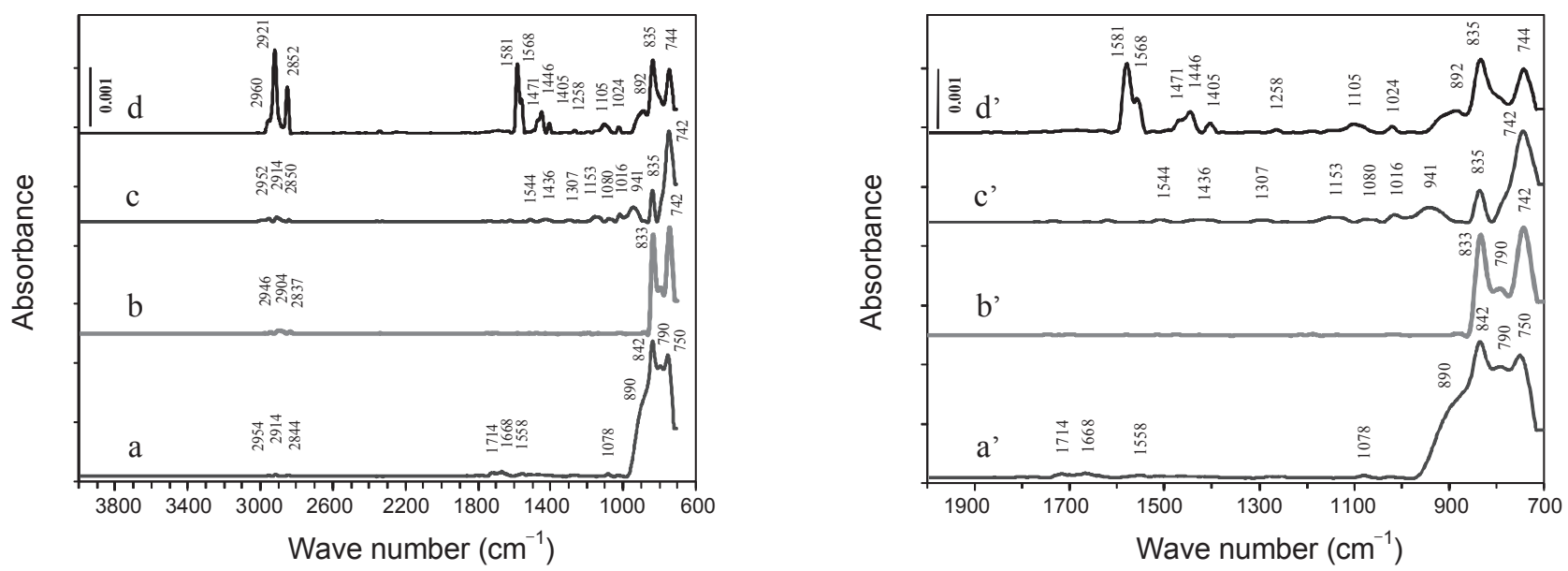

Figure 5. IR spectra for carbon-coated Si electrode obtained after cycling (a) without silane, and with (b) 1-(trimethylsilyloxy)-1,3-butadiene, (c) methyltrimethoxysilane and (d) tris(2-methoxyethoxy)vinylsilane between 0.1 and $1.5 \mathrm{~V} v s$. $\mathrm{Li} / \mathrm{Li}^{+}$, followed by DMC washing and drying, and (a')-(d') their magnifications. 
bance peaks near $1471-1405 \mathrm{~cm}^{-1}$ come from the deformation of alkyl group. Remind that after self-assembly the film showed the alkyl and other functionallities from silane moiety (Fig. 2c'-c'). The presence of silane moiety and/or polymerization of vinyl group of silane contributes to enhancement of absorbance of alkyl group. Another strong peaks at 1581 and $1568 \mathrm{~cm}^{-1}$ are assigned to $\mathrm{C}=\mathrm{O}$ carbonyl group of $\mathrm{R}-\mathrm{CO}_{2}{ }^{-} \mathrm{M}^{\mathrm{n}+}$ $(\mathrm{R}=$ alkyl, $\mathrm{M}=\mathrm{Li} / \mathrm{Si})$ carboxylate metal salt functionalities in different chemical bonding nature of $-\mathrm{CO}_{2}{ }^{-31,32}$ Lower absorbance peaks near $1260-1020 \mathrm{~cm}^{-1}$ attributed to finger prints of $\mathrm{C}=\mathrm{O}$ and $\mathrm{C}-\mathrm{O}$ stretching of carboxylate support this assignment. ${ }^{31,32}$ Alkyl and carboxylate metal salt groups are included to the decomposition products of carbonate-based organic solvents (EC, DEC). Intense features from organic phosphorusfluorine compounds and other P-F containing inorganic species are also observed in the region of $1260-835 \mathrm{~cm}^{-1} .31,32,43$ Overlapping of a number of peaks in the region of $900-800 \mathrm{~cm}^{-1}$ including P-F stretchings enhances the peak near $835 \mathrm{~cm}^{-1}$. For the peak weakening of the funtionalities for siloxane and silane moiety, the SEI layer components must be in a higher concentration level than them, thereby, their peaks are hidden under other intense peaks from SEI components. Effective surface passivation of the electrode by those accumulated SEI species is of benefit in protecting the film surface from direct interfacial reaction with electrolyte, improving capacity retention as observed in Fig. 3d-d' and 4.

The IR analysis results indicate that the SEI layer formed by cycling with tris(2-methoxyethoxy)(vinyl)silane is composed of mainly organic compounds with the functionalities of alkyl, and carboxylate metal salt, and inorganic compounds including organic phosphorus compounds and other P-F containing species. Self-assembled siloxane and the presence of silane moieties induced the formation of a plenty of the SEI components. Since more stable capacity retention of the C-Si was attained when large amounted organic and PF-containing inorganic SEI compounds were produced, the efficient protection of the C-Si surface with high coverage siloxane network is believed to be the origin of improved electrochemical performance.

Morphology changes with cycling. Morphology change in the $\mathrm{C}$-Si due to cycling was examined using ex-situ SEM. Figure $6 \mathrm{a}-\mathrm{d}$ show the surface SEM images of the C-Si after 200 cycles without and with silanes. After cycling without silane, Fig. 6a, film cracking was severe and film appeared brittle, as often observed on Si-based alloy materials. ${ }^{4-6}$ Film surface obtained after cycling with 1-(trimethylsilyloxy)-1,3-butadiene, Fig. 6b, was quite a coarse and porous. The particles were somewhat separated from each other. Drastic performance decline during cycling (Fig. 3b-b' and 4) is correlated to this severe morphology change, supporting that surface protection was inferior (Fig. 5b-b'). With methyltrimethoxysilane, Fig. 6c, overall film surface was relatively smooth but film had cracks, although the film appeared still dense. By contrast, with tris(2-methoxyethoxy)vinylsilane the film surface, Fig. $6 \mathrm{~d}$, remained smooth, with several round particles in the diameter of $70-330 \mathrm{~nm}$. Neither film cracking nor particle aggregation was observed. Surface modification with high coverage siloxane network was effective in reducing the mechanical disintegration of particles. This de-
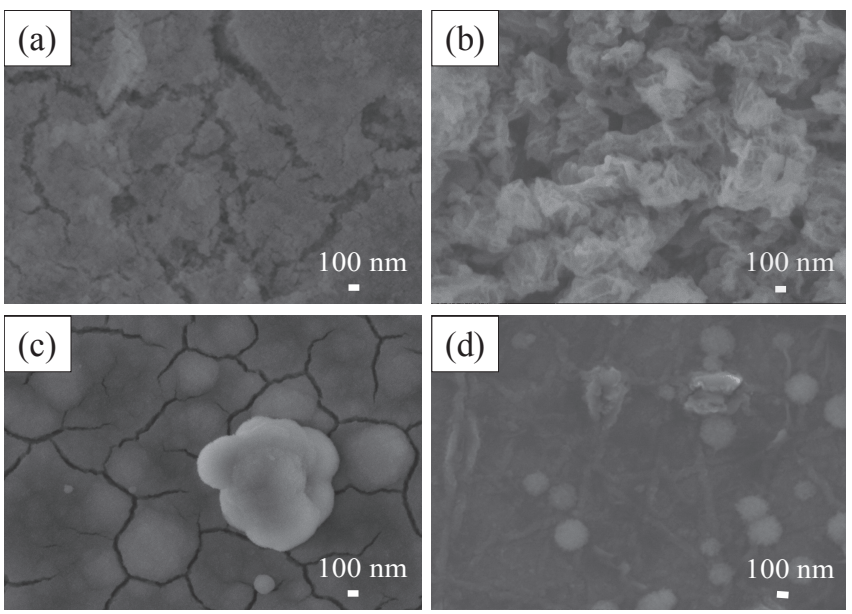

Figure 6. SEM images of surface morphology for carbon-coated Si electrode obtained after cycling (a) without silane, and with (b) 1-(trimethylsilyloxy)-1,3-butadiene, (c) methyltrimethoxysilane and (d) tris(2-methoxyethoxy)vinylsilane.

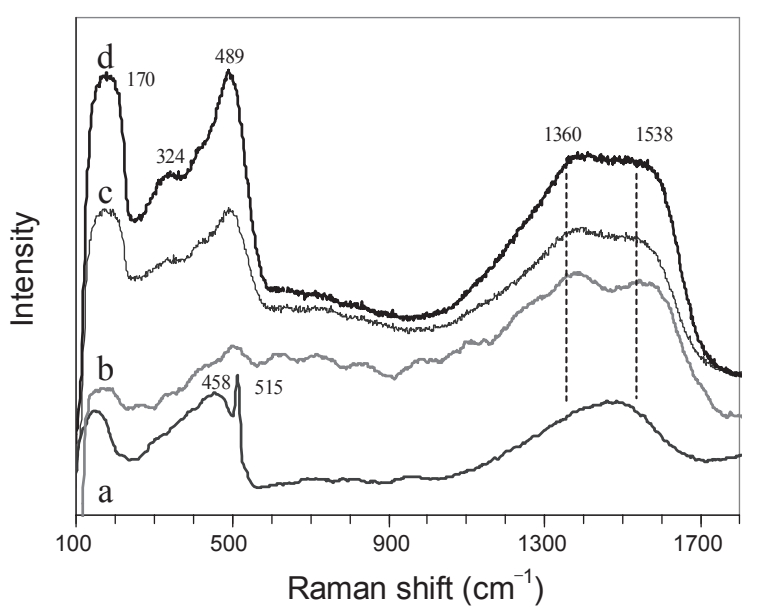

Figure 7. Raman spectra for carbon-coated Si electrode obtained after cycling (a) without silane and with (b) 1-(trimethylsilyloxy)-1,3butadiene, (c) methyltrimethoxysilane and (d) tris(2-methoxyethoxy) vinylsilane.

monstrates that film morphology change of the $\mathrm{C}$-Si with cycling is strongly dependent on surface chemistry.

Raman spectroscopy provided supportive information on changes in film morphology and surface composition on the C-Si. Figure 7 shows Raman spectra of the C-Si obtained after 200 cycles without and with silanes. After cycling without silane, the spectral feature (Fig. 7a) of the film resembles the as-prepared film (Fig. 1b). However, with cycling in the presence of silanes the films showed spectral changes. In Fig. 7b-d, the sharp band at $515 \mathrm{~cm}^{-1}$ from crystalline $\mathrm{Si}^{27}$ disappeared but a new band at $489 \mathrm{~cm}^{-1}$ characteristic of amorphous Si appeared instead. ${ }^{28,29}$ All crystalline Si must be converted to amorphous $\mathrm{Si}$, consistent with previous report. ${ }^{16}$ Newly noticed was the appearance of a strong and broad band near $1360 \mathrm{~cm}^{-1}$ due to diamond-like $\mathrm{sp}^{3}$ carbon (D-band). ${ }^{30,31}$ Diamond-like carbon is associated with the presence of organic SEI compounds and siloxane, which include $\mathrm{sp}^{3}$-coordinated carbon. Or graphite- 
like carbon (G-band), which was originally of the as-prepared $\mathrm{C}-\mathrm{Si}$, could be partly converted to diamond-like one by cycling.

\section{Conclusions}

The surface of carbon-coated Si was modified by self-assembly of siloxane network using monoalkoxy-, trialkoxy- and trialkoxy-silane with long oxaethylene chain as additives for stabilizing cycling performance of carbon-coated $\mathrm{Si}$ in the electrolyte of $1 \mathrm{M} \mathrm{LiPF}_{6} / \mathrm{EC}: \mathrm{DEC}$. The use of longer chain trialkoxysilane was effective in building up 3D siloxane network with high surface coverage and suppressing direct electrode/electrolyte interfacial reaction after the early stage of cycling, which increased the reversibility in cycling. Self-assembled siloxane network led to the formation of a stable SEI layer primarily consisting of organic compounds and PF-containing inorganic species. Simultaneously particle cracking event was efficiently reduced, and capacity value and retention were dramatically improved. Since cycling performance, surface composition and particle morphology change were strongly dependent on the surface coverage of siloxane network, the selection of an appropriate silane is of great impact on the performance control of carbon-coated Si. The data suggest that the control of surface chemistry is necessary to attain high performance lithium-ion batteries employing Si-based alloy anode materials.

Acknowledgments. This work was supported partly by Midcareer Researcher Program (No.2009-0083817) and partly Basic Science Research Program (NRF-2009-0070922) through the National Research Foundation of Korea funded by the Ministry of Education, Science and Technology.

\section{References}

1. Netz, A.; Huggins, R. A.; Weppner, W. J. Power Sources 2003, 119-121, 95

2. Hatchard, T. D.; Dahn, J. R. J. Electrochem. Soc. 2004, 151, A838.

3. Obrovac, M. N.; Christensen, L. Electrochem. Solid-State Lett. 2004, 7, A93.

4. Beaulieu, L. Y.; Eberman, K. W.; Turner, R. L.; Krause, L. J.; Dahn, J. R. Electrochem. Solid-State Lett. 2001, 4, A137.

5. Lee, S. J.; Lee, J. K.; Chung, S. H.; Lee, H. Y.; Lee, S. M.; Baik, H. K. J. Power Sources 2001, 97-98, 191.

6. Kasavajjula, U.; Wang, C.; Appleby, A. J. J. Power Sources 2007, 163,1003 .

7. Obrovac, M. N.; Krause, L. J. J. Electrochem. Soc. 2007, 154, A103.

8. Dimov, N.; Kugino, S.; Yoshio, M. Electrochim. Acta 2003, 48, 1579.

9. Ng, S.-H.; Wang, J.; Wexler, D.; Konstantinov, K.; Guo, Z.-P.; Liu, H.-K. Angew. Chem. Int. Ed. 2006, 45, 6896.

10. Niu, J.; Lee, J. Y. Electrochem. Solid-State Lett. 2002, 5, A107.

11. Yang, J.; Wang, B. F.; Wang, K.; Liu, X. Y.; Wen, Z. S. Electrochem. Solid-State Lett. 2003, 6, A154.

12. Saint, J.; Morcrette, M.; Larcher, D.; Laffont, L.; Beattie, S.; Pérès,
J.-P.; Talaga, D.; Couzi, M.; Tarascon, J.-M. Adv. Funct. Mater. 2007, 17, 1765.

13. Esmanski, A.; Ozin, G. A. Adv. Funct. Mater. 2009, 19, 1999.

14. Kim, H.; Han, B.; Choo, J.; Cho, J. Angew. Chem. Int. Ed. 2008, $120,10305$.

15. Hochgatterer, N. S.; Schweiger, M. R.; Koller, S.; Raimann, P. R.; Wöhrle, T.; Wurm, C.; Winter, M. Electrochem. Solid-State Lett. 2008, $11, \mathrm{~A} 76$

16. Song, S.-W.; Baek, S.-W. Electrochem. Solid-State Lett. 2009, 12 , A23.

17. Zhuang, G. V.; Ross, P. N., Jr. Electrochem. Solid-State Lett. 2003 , 6, A136.

18. Ryu, Y.-G.; Lee, S.; Mah, S.; Lee, D. J.; Kwon, K.; Hwang, S.; Doo, S. J. Electrochem. Soc. 2008, 155, A583.

19. Choi, N. S.; Yew, K. H.; Lee, K. Y.; Sung, M.; Kim, H.; Kim, S.-S. J. Power Sources 2006, 161, 1254.

20. Ulman, A. Chem. Rev. 1996, 96, 1533.

21. Striebel, K. A.; Deng, C. Z.; Wen, S. J.; Cairns, E. J. J. Electrochem. Soc. 1996, 143, 1821

22. Song, S.-W.; Reade, R. P.; Cairns, E. J.; Vaughey, J. T.; Thackeray, M. M.; Striebel, K. A. J. Electrochem. Soc. 2004, 151, A1012.

23. Baek, S.-W.; Hong, S.-J.; Kim, D.-W.; Song, S.-W. J. Power Sources 2009, 189, 660.

24. Song, S.-W.; Baek, S.-W. Electrochim. Acta 2009, 54, 1312.

25. Zhuang, G. V.; Xu, K.; Yang, H.; Jow, T. R.; Ross, P. N., Jr. J. Phys. Chem. B 2005, 109, 17567.

26. Compton, S. V.; Compton, D. A. C. In Practical Sampling Techniques for Infrared Analysis; Coleman, P. B., Ed.; CRC Press: Boca Raton, FL, 1993.

27. Han, D.; Lorentzen, J. D.; Weinberg-Wolf, J.; McNeil, L. E. J. Appl. Phys. 2003, 94, 2930.

28. Brodsky, M. H.; Cardona, M.; Cuomo, J. Phys. Rev. B 1977, 16, 3556.

29. Baranchugov, V.; Markevich, E.; Pollak, E.; Salitra, G.; Aurbach, D. Electrochem. Commun. 2007, 9, 796.

30. Tuinstra, F.; Koenig, J. L. J. Chem. Phys. 1970, 53, 1126.

31. Colthup, N. B.; Daly, L. H.; Wiberley, S. E. Introduction to Infrared and Raman Spectroscopy; Academic Press: New York, 1990.

32. Socrates, G. Infrared Characteristic Group Frequencies, Tables and Charts; John Wiley \& Sons: New York, 1994.

33. Spectral database for organic compounds SDBS, http://riodb01. ibase.aist.go.jp/sdbs

34. Zhang, X.; Kostecki, R.; Richardson, T. J.; Pugh, J. K.; Ross, P. N., Jr. J. Electrochem. Soc. 2001, 148, A1341.

35. Xu, K. Chem. Rev. 2004, 104, 4303.

36. Aurbach, D.; Markovsky, B.; Shechter, A.; Ein-Eli, Y. J. Electrochem. Soc. 1996, 143, 3809 .

37. Limthongkul, P.; Jang, Y.-I.; Dudney, N. J.; Chiang, Y.-M. Acta Materialia 2003, 51, 1103 .

38. Schroeder, G.; Gierczyk, B.; Waszak, D.; Walkowiak, M. Electrochem. Commun. 2006, 8, 1583.

39. Santner, H. J.; Korepp, C.; Winter, M.; Besenhard, J. O.; Moller, K.-C. Anal. Bioanal. Chem. 2004, 379, 266.

40. Aurbach, D.; Moshkovich, M.; Cohen, Y.; Schechter, A. Langmuir 1999, 15, 2947.

41. Matsuta, S.; Asada, T.; Kitaura, K. J. Electrochem. Soc. 2000, 147, 1695.

42. Zhuang, G. V.; Yang, H.; Blizanac, B.; Ross, P. N., Jr. Electrochem. Solid-State Lett. 2005, 8, A441.

43. Yang, H.; Zhuang, G. V.; Ross, P. N., Jr. J. Power Sources 2006, 161, 573. 